\title{
Effects of land use/cover change on land surface energy partitioning and climate in Northeast China
}

\author{
Fengshan Liu • Fulu Tao • Jiyuan Liu • Shuai Zhang • \\ Dengpan Xiao • Meng Wang • He Zhang • Huizi Bai
}

Received: 13 April 2014 / Accepted: 7 December 2014 / Published online: 24 December 2014

(C) Springer-Verlag Wien 2014

\begin{abstract}
The Simple Biosphere Model (SiB2) and the $2 \times$ $2 \mathrm{~km}$ resolution National Land use/Land Cover database were used to investigate the effects of Land Use/Cover Change (LUCC) on land surface energy balance and climate in Jilin Province, northeast China, from 1990 to 2005. The spatial patterns of the components of surface energy balance (i.e., net radiation $\left(R_{\mathrm{n}}\right)$, latent heat $(\mathrm{LH})$, sensible heat $(\mathrm{SH})$, and albedo $(\alpha)$ ) and climate (i.e., canopy temperature $\left(T_{\mathrm{c}}\right)$, diurnal temperature range (DTR)), as well as the roles of land cover type in variations of energy balance and climate, were investigated. The results showed that there were general similar trends in $R_{\mathrm{n}}, \mathrm{LH}, \mathrm{SH}$, and $\alpha$ in the LUCC process. The spatial patterns of $T_{\mathrm{c}}$ and DTR also showed consistent relationships with LUCC processes. Leaf area index (LAI) and canopy conductance $\left(g_{\mathrm{c}}\right)$ were found to be the key factors in controlling the spatial patterns of the components of surface energy balance and $T_{\mathrm{c}}$. Using linear correlation method, the gaps of the components of surface energy balance were well-explained by the differences of LAI and $g_{\mathrm{c}}$, and $R_{\mathrm{n}}$ had a better correlation with $T_{\mathrm{c}}$ and DTR, in the process of LUCC. The surface energy partitioning of $R_{\mathrm{n}}$ into LH and SH could not only dampen or strengthen the temperature difference, but also
\end{abstract}

F. Liu $\cdot$ F. Tao $(\bowtie) \cdot$ J. Liu $\cdot$ S. Zhang $\cdot$ M. Wang $\cdot$ H. Zhang $\cdot$ H. Bai Institute of Geographic Sciences and Natural Resources Research, Chinese Academy of Sciences, Beijing 100101, China

e-mail: taofl@igsnrr.ac.cn

\section{F. Liu}

Juncao Research Institute, Fujian Agriculture and Forestry

University, Fuzhou 350002, Fujian, China

D. Xiao

Institute of Geographical Sciences, Hebei Academy of Sciences, Shijiazhuang 050011, China

M. Wang $\cdot$ H. Zhang $\cdot$ H. Bai

University of Chinese Academy of Sciences, Beijing 100049, China change the relative size of albedo-based $R_{\mathrm{n}}$ when the albedo gap was small, between land cover types.

\section{Introduction}

Land Use/Cover Change (LUCC) influences energy budget and climate by providing different biogeophysical processes, i.e., surface albedo, roughness length, canopy conductance $\left(g_{\mathrm{c}}\right)$, for the change of plant height, canopy structure, leaf area index (LAI), fraction of photosynthetically active radiation absorbed by the canopy (FPAR), stomatal character, and root depth. Those biogeophysical processes have tiny modification at global scale (e.g., albedo reduced global mean radiative forcing by $-0.2 \mathrm{~W} \mathrm{~m}^{-2}$ (IPCC 2007)), but play a significant role on energy balance at regional scale. The biogeophysical forcing of LUCC may, in some regions, be of similar magnitude or larger than that of greenhouse gas-induced climate change (e.g., Bonan 2008; Avila et al. 2012; Mahmood et al. 2013). Avila et al. (2012) also demonstrated that impacts of LUCC on indices of temperature extreme were equal to the impacts of doubling of $\mathrm{CO}_{2}$, which pointed out the influence of LUCC on regional climate (e.g., Gao et al. 2003; Lawrence and Chase 2010; Boisier et al. 2012; Wang et al. 2013). So information on global mean radiative forcing and global mean surface temperature change may be less useful than information on regional climate changes including precipitation (Betts et al. 2007).

The significant LUCC types include agriculture, forest, and grassland (Mahmood et al. 2013). Forest usually has lower short-wave albedo than grassland or farmland (Bonan 2002). Lower albedo, which means more solar radiation trapped by ecosystem, will facilitate the rise of temperature. So temperature reduction caused by deforestation firstly roots in increased albedo. Many studies showed this consistent trends and the associated near-surface cooling as the leading impact of LUCC (e.g., Feddema et al. 2005; Wang et al. 2013). The 
LUCC-induced cooling is directed by increase in albedo, but its amplitude is 30 to $50 \%$ smaller than the one that would be expected from the sole radiative changes (Boisier et al. 2012). The non-radiative processes, including the energy partitioning into latent and sensible heat and roughness length, are the main reasons. The reclamation of forest into farmland or grassland reduces the surface roughness length, and the consequent reduction in turbulent energy fluxes and increase of surface temperature. The partitioning of net radiation into latent and sensible heat depends on LAI, $g_{c}$, root distribution, and soil texture (Bonan 2002). Crops often have larger evaporation rates, if the water supply is sufficient during spring and summer, than forest in temperate climate zone (Baldocchi et al. 1997; Teuling et al. 2009; Boisier et al. 2012), which reduces surface temperature with albedo. In contrast, crops in lower or higher latitude are not as productive and efficient as in temperate region, which is helpful in increasing surface temperature.

The effects of deforestation on surface temperature in northeast China had been investigated. For example, Gao et al. (2003), using RegCM2 model and NCAR LUCC data, found increased surface temperature with deforestation in our study area. Lawrence and Chase (2010), using Community Climate System Model (CCSM) and MODIS LUCC data, revealed that the deforestation in the past reduced the LAI but increased albedo in all four seasons; air temperature was increased in summer and autumn but decreased in winter and spring. Wang et al. (2013), using WRF model and MODIS LUCC data, also discovered that LAI reduced, albedo increased, and surface temperature decreased in both summer and winter from 2006 to 2011. The cause primarily comes from the influence of radiative process. But they did not elaborate to analyze the impact of nonradiative process, which is important in retarding temperature change. Also, LUCC-driven climate change depends on local conditions such as the underlying surface albedo and soil moisture availability (Betts 2001), as well as the model and LUCC data used in the simulation.

In this study, we investigated the changes of surface energy partitioning, albedo, LAI, $g_{c}$, and climate under the influence of LUCC. The linear correlation method was used to estimate the impacts of vegetation on net radiation, sensible heat, latent heat and albedo, and climate as canopy temperature and diurnal temperature range (DTR). The contributions of energy balance components to canopy temperature were also discussed in the article. The experimental design and data are presented in Section 2. Section 3 describes the impacts and mechanisms of LUCC on energy partitioning and temperature changes. Conclusions and discussion are provided in Section 4.

\section{Material and method}

\subsection{Study area}

The study area is located in Jilin Province, northeast China, which had undergone rapid transformation among forest, grassland, and farmland in the past three decades (Figs. 1 and 2). In the study area, grassland was mainly distributed in the northwest, deciduous forest was in the east, and farmland was widely dispersed but especially concentrated in the center of Jilin. The land cover was changed from grassland to farmland in the northwest, and from forest to grassland and from forest to farmland in the center and east from 1990 to 2005, respectively (Fig. 2). During 1990-2005, the obvious transformation was forest reclamation into farmland $\left(4468 \mathrm{~km}^{2}\right)$ and grassland into farmland $\left(2920 \mathrm{~km}^{2}\right)$. The area $\left(\mathrm{km}^{2}\right)$ of conversion was 412 from farmland to grassland, 644 from forest to grassland, 1816 from farmland to forest, and 1204 from grassland to forest.

\subsection{Model}

The Simple Biosphere Model (SiB2) of Sellers et al. (1996a, 1996b) was used to assess the effects of change in vegetation (farmland, grassland, forest) on surface energy balance and climate. The model aggregates to a manageable number (9) of vegetation classes, i.e., broad-leaf evergreen trees, broad-leaf deciduous trees, broad-leaf and needle-leaf trees, needle-leaf evergreen trees, needle-leaf deciduous trees, short vegetation, shrubs with bare soil, dwarf trees and shrubs, and agriculture or $\mathrm{C} 3$ grasslands. The classification is based on plant energy balance and life form dynamics, as these are the most useful

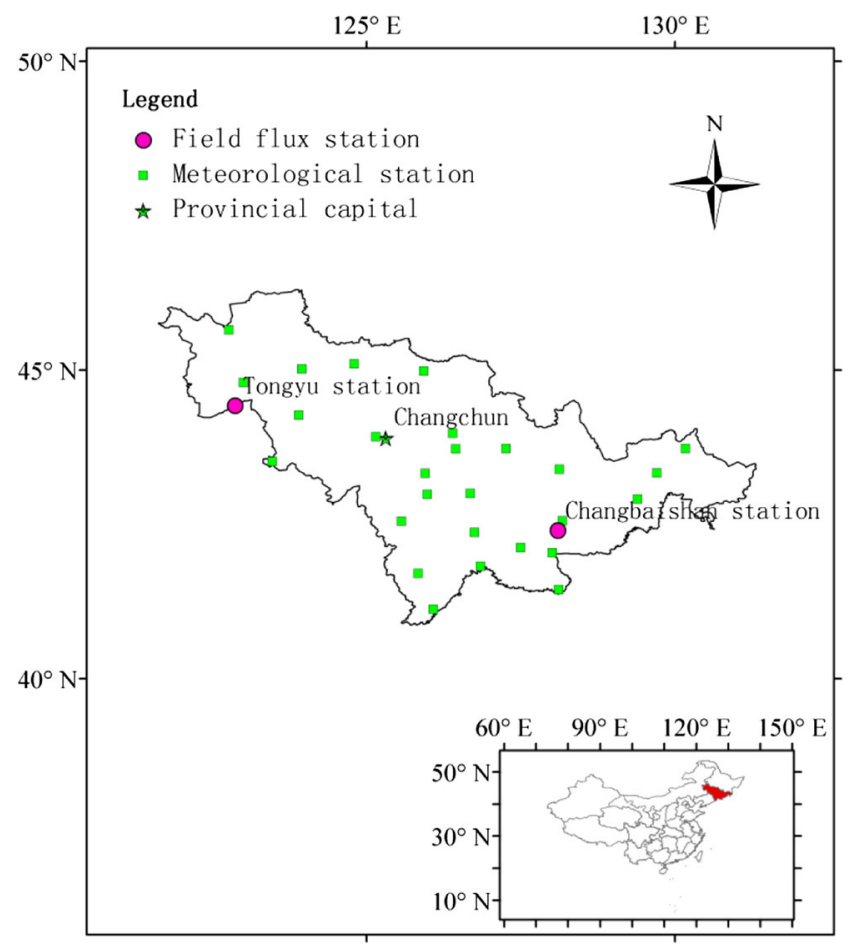

Fig. 1 The study area. Spatial meteorological data with resolution of $2 \times$ $2 \mathrm{~km}$ was interpolated using meteorological station records by inverse distance weighting method; model-calibration flux data was measured at Tongyu station and Changbaishan station both at the entire 2003 
Fig. 2 Land cover change across the study area in 1990-2005

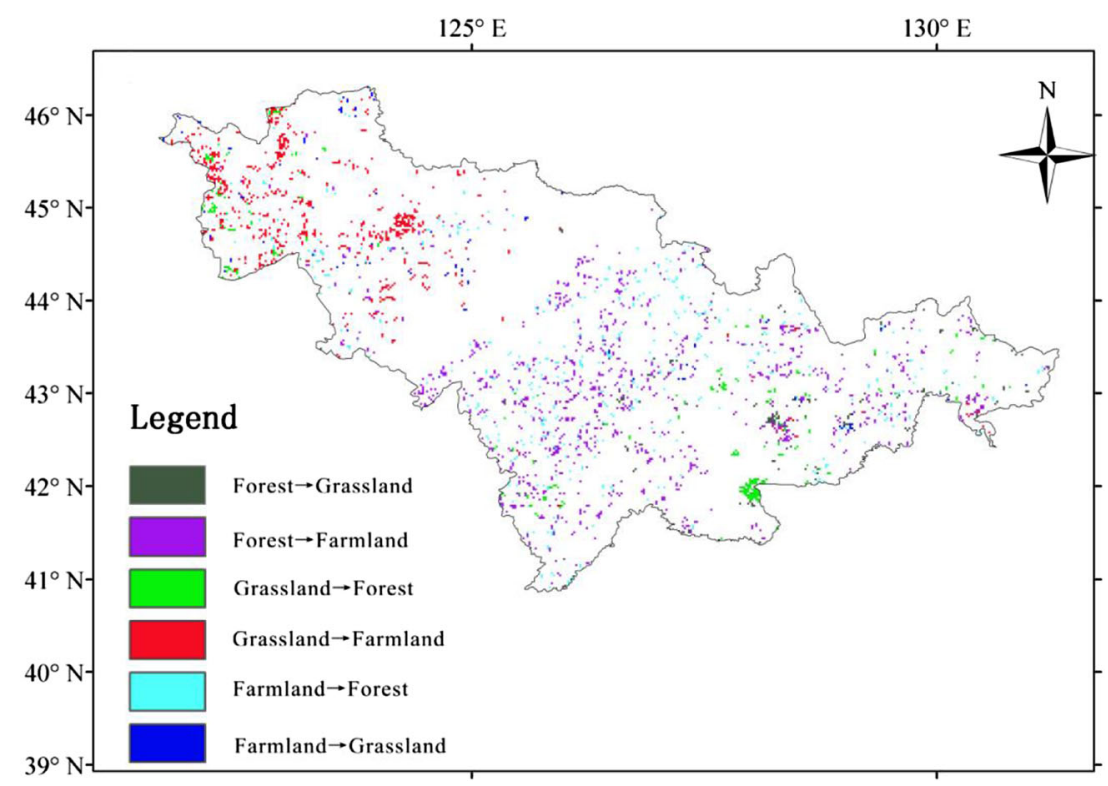

for coupling the land surface with atmospheric chemistry and physics (Potter et al. 1993).

The energy partitioning of a terrestrial surface is expressed as follows:

$(1-\alpha) S_{\mathrm{d}}+L_{\mathrm{d}}-L_{\mathrm{u}}=\mathrm{LH}+\mathrm{SH}+G$

Where $\alpha$ is the surface albedo, $S_{\mathrm{d}}, L_{\mathrm{d}}$, and $L_{\mathrm{u}}$ are the downward short-wave radiation, downward long-wave radiation, and upward long-wave radiation, respectively. The right side of Eq. (1) represents the partitioning of absorbed radiation by earth surface $\left(R_{\mathrm{n}}\right)$ into latent heat $(\mathrm{LH})$, sensible heat $(\mathrm{SH})$, and ground heat flux $(G)$.

Based on plant physiological processes, $\mathrm{SiB} 2$ includes a coupled photosynthesis-conductance submodel to simulate the simultaneous exchange of water vapor in and out of the leaf and canopy, and to regulate the partitioning of net radiation into latent and sensible heat flux. The $g_{\mathrm{c}}$ could be computed according to Collatz et al. (1991, 1992), which combined a photosynthetic model with semi-empirical model for leaf stomatal conductance model. The surface albedo from soil and canopy reflectance is calculated by a two-stream approximation in the visible and near-infrared wavelength intervals (Sellers 1985). The fluxes of heat and water are computed from the potential differences of temperature and vapor pressure and from aerodynamic resistances that depend on the roughness length (Sellers et al. 1996a). Therefore, vegetation change affects all components of energy and water balance (Pongratz et al. 2006).

Though SiB2 has been validated in a number of ecosystems such as forest, grassland, and cropland (Yan et al. 2010), we further checked the simulation ability in energy balance and canopy temperature against site-specific measuring data at Tongyu station for farmland and grassland and at Changbaishan station for deciduous forest (Liu et al. 2014). The results suggest that $\mathrm{SiB} 2$ can capture well the variations of energy balance and canopy temperature, using parameters listed in Table 1. These parameters were also used in the simulation at regional scale. The simulated temperature and precipitation were further validated against the sitetemperature and precipitation obtained from the China Meteorological Administration (Fig. 1), as shown in Section 3.1.

\subsection{Data}

\subsubsection{Land cover classifications}

The land cover maps used in this study are derived from the $2 \times 2 \mathrm{~km}$ resolution National Land use/Land Cover (NLLC)

Table 1 The classification and parameters used in SiB2 simulation

\begin{tabular}{llllllll}
\hline Classification & z1 & z2 & zc & www(1) & www(2) & www(3) \\
\hline Farm & 0.1 & 2 & 1.2 & 0.245 & 0.522 & 0.523 \\
Grass & 0.06 & 0.1 & 0.08 & 0.367 & 0.583 & 0.588 \\
Forest & 8.0 & 26.0 & 15.0 & 0.286 & 0.436 & 0.381 & 6.0 \\
\hline
\end{tabular}

z1: Canopy-base height (m); z2: canopy-top height (m); zc: inflection height for leaf area density (m); www(1-3): wetness of surface layer, root zone, and recharge zone, separately; gradm: conductance-photosynthesis slope parameter $\left(\mathrm{mol} \mathrm{m}^{-2} \mathrm{~s}^{-1}\right)$ 
raster databases for two time periods: 1990 and 2005, which are based on the advanced very high resolution radiometer (AVHRR) images and geo-physical datasets (e.g., climate, elevation) (Liu et al. 2002, 2009). The NLLC classification, including six main land cover types: farmland, forest, grassland, water body, urban and build-up, and unused land, is different from the vegetation classification of $\mathrm{SiB} 2$. It is necessary to reclassify the NLLC classification according to the requirement of the SiB2. Since our research focus on the conversion between farmland, forest, and grassland, the classification of agriculture/C3 grassland in $\mathrm{SiB} 2$ was separated into two groups with different parameters as shown in Table 1. The classification of forest in NLLC is represented by the broad-leaf and needle-leaf trees in SiB2 (Zhao et al. 2004), with modified parameters shown in Table 1 . The other classes, such as water body, urban and build-up, and unused land, were not simulated.

The parameters used in $\mathrm{SiB} 2$ simulation were validated against site-specific energy balances. The site-specific energy balances used in this study were obtained from Tongyu field observation station $\left(44^{\circ} 25^{\prime} \mathrm{N}, 122^{\circ} 52^{\prime} \mathrm{E}, 184\right.$ masl) for farmland and grassland, and from Changbaishan station $\left(42^{\circ}\right.$ $24^{\prime} \mathrm{N}, 128^{\circ} 6^{\prime} \mathrm{E}, 738$ masl) for forest (Fig. 1). The heights (z1, $\mathrm{z} 2$, and zc) needed in SiB2 were obtained from Yan et al. (2010) for farmland and grassland, and from Wang et al. (2004) for forest. To obtain the initial conditions, soil wetness (www (1-3)) for all soil layers were set at 0.6 of soil saturation. Then, the simulation was run 50 times with 2003 forcing data until the soil moisture reached at a seasonally repeating equilibrium state. The conductance-photosynthesis slope parameter (gradm) has important influence on stomatal behavior, and are varying between 3.4 and $10 \mathrm{~mol} \mathrm{~m}^{-2} \mathrm{~s}^{-1}$ with vegetation types (Hanan et al. 2005(Table 1)). We calibrated it to improve the simulation accuracy over farmland and grassland. All other parameter values were set using biome-specific values and algorithms provided by Sellers et al. (1996b).

\subsubsection{Vegetation dynamic}

Spatial and temporal data of LAI and FPAR were used to represent the time-varying phenological properties of vegetation. LAI data were obtained from the leaf area index product data collection (Liang and Xiao 2012). FPAR data was derived through the following equation (Sellers et al. 1996b):

$\mathrm{FPAR}=V \times N(1-\exp (\mathrm{LAI} /(-N \bar{\kappa})))$

Where

$\mathrm{V}$ Vegetation cover fraction

$\mathrm{N}$ Canopy greenness fraction $\bar{\kappa} \quad$ Time-mean (radiation-weighted) extinction coefficient for PAR.

\subsubsection{Soil and atmospheric data}

To assess the sensitivity of surface energy and canopy temperature to land cover changes, all drives other than land cover and vegetation dynamics were identical between simulations.

The soil data required by the model were given by one of the seven soil texture types each assigned a set of physical parameters (Sellers et al. 1996b). The soil texture map is derived from the Food and Agriculture Organization (FAO) at $2 \times 2 \mathrm{~km}$ resolution matching the vegetation data. The impact on energy balance and climate is negligible since the soil is kept identical in all simulations.

The atmospheric drivers for $\mathrm{SiB} 2$ include downward shortwave radiation, downward long-wave radiation, water vapor pressure, air temperature, wind speed, and precipitation. The $2 \times 2 \mathrm{~km}$ resolution data was obtained by interpolating the daily dataset from meteorological stations in the study region with the inverse distance weighting method. Then, the daily record downscaled into hourly data according to Tang et al. (2006). Downward short-wave radiation was calculated according to Revfeim(1997) and Yang et al. (2001). Downward long-wave radiation was computed by air temperature and vapor pressure. Water vapor pressure calculation equation can be found in Kimball et al. (1997). The model used for temperature downscale was Carla Cesaraccio et al. (2001).

Not only the atmospheric data but also the surface energy balance process was measured at Tongyu field observation station. These data were used to test the interpolation quality and simulation results (Liu et al. 2014). The comparison results showed high quality for interpolated temperature and wind speed, and showed worse accuracy for precipitation because of its nonlinear and spatial variation. The calibration and validation test uncovered that this inaccuracy did not alter the annual change trend of the components of surface energy balance, and did change the annual average of simulated $R_{\mathrm{n}}$ by $-5.1,-8.4$, and $-3.7 \%$; of simulated LH by $-10.5,-16.3$, and $-12.3 \%$; of simulated SH by $6.7,3.9$, and $2.5 \%$, at farmland, grassland, and forest, respectively.

\subsection{Experimental designs and method}

Canopy temperature change mimicked by model is impacted by both radiative and non-radiative processes. In order to calculate temperature variation caused by the sole change in short-wave radiation (radiative process), the following equation (Boisier et al. 2012) was used:

$$
\Delta T=(\varepsilon \sigma)^{-1 / 4}\left[\left(L_{\mathrm{u}}+\Delta L_{\mathrm{u}}\right)^{1 / 4}-L_{\mathrm{u}}{ }^{1 / 4}\right]
$$


Where $\Delta T$ is the variation of canopy temperature $\left({ }^{\circ} \mathrm{C}\right)$. The surface emissivity $(\varepsilon)$ is set to 1.0 . A perturbation in $S_{\mathrm{d}}, L_{\mathrm{d}}$, $\mathrm{LH}, \mathrm{SH}$, or $G$ can be expressed as $\Delta L_{\mathrm{u}}$ by fixing nonperturbed terms using Eq. (1).

Two experiments were conducted to study the effects of LUCC on surface energy balance and climate. The two experiments were conducted with different land cover data of 1990 and 2005, driving by the same atmospheric forcing from 2001 to 2010, respectively. The comparisons between simulations were conducted at each four seasons (winter, spring, summer, and autumn) based on the 10-year average.

\section{Results}

In this section, firstly, we described the changes of the components of surface energy balance and canopy temperature due to the LUCC. Next, we analyzed the regional statistical relationships between the components of surface energy balance, canopy temperature, and LAI, $g_{\mathrm{c}}$, to show the regulation of vegetation. Finally, we decoupled the effects of nonradiative process from radiative process on canopy temperature.

3.1 The impacts of LUCC on energy partitioning and canopy temperature

\subsubsection{The effects of LUCC on the variations of energy partitioning}

$G$ was not analyzed in this article because of its smaller proportion compared with latent heat and sensible heat flux in net radiation. As shown in Fig. 3, the LUCC types had important influences on (a) $R_{\mathrm{n}}$, (b) $\mathrm{LH}$, (c) SH, and (d) $\alpha$. The conversion from forest to grass decreased $R_{\mathrm{n}}$ by $-20.1 \sim$ $-7.4 \mathrm{~W} \mathrm{~m}^{-2}$, decreased LH by up to $-9 \mathrm{~W} \mathrm{~m}^{-2}$, decreased SH by $-24.7 \sim-7.6 \mathrm{~W} \mathrm{~m}^{-2}$, and increased $\alpha$ by $0.02 \sim 0.1$. The conversion from forest to farm decreased $R_{\mathrm{n}}$ and $\mathrm{SH}$ by $-19.6 \sim-5.6$ and $-31.9 \sim-8 \mathrm{~W} \mathrm{~m}^{-2}$, and increased $\alpha$ by $0.03 \sim 0.11$, respectively. But LH was mainly increased by $-5.2 \sim 16.9 \mathrm{~W} \mathrm{~m}^{-2}$. The conversion from grass to farm
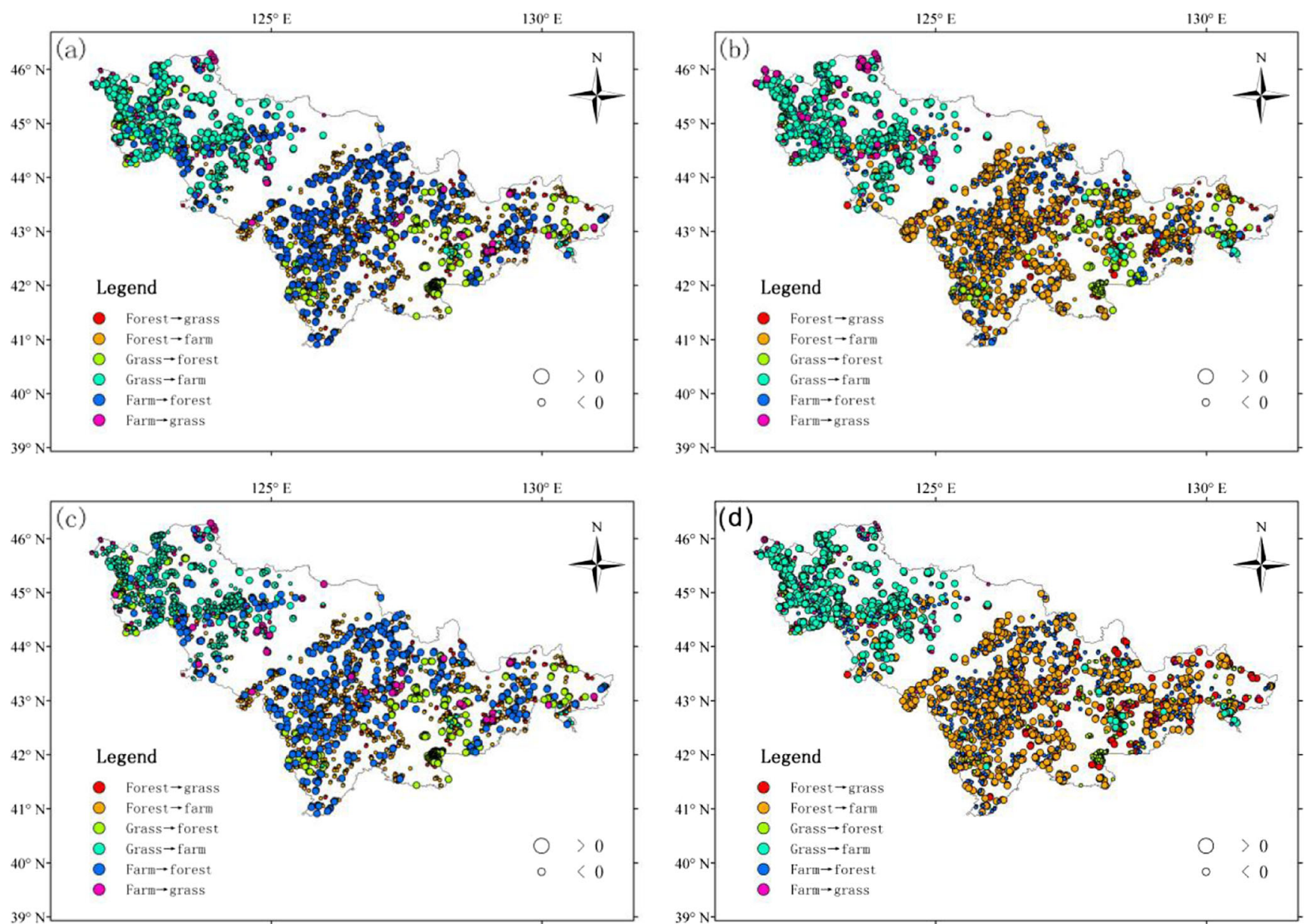

Fig. 3 The spatial pattern of LUCC-induced impacts on net radiation $\left(\mathbf{a}, \mathrm{W} \mathrm{m}^{-2}\right)$, latent heat flux $\left(\mathbf{b}, \mathrm{W} \mathrm{m}^{-2}\right)$, sensible heat $\left(\mathbf{c}, \mathrm{W} \mathrm{m}^{-2}\right)$, and albedo $(\mathbf{d})$. Colors mean the land use change types. Large (small) circle represents a positive (negative) impact 
primarily enhanced the ecosystem absorption of $R_{\mathrm{n}}$ by $-2.5 \sim$ $4.3 \mathrm{~W} \mathrm{~m}^{-2}$, strengthened the partitioning into LH by $-4.9 \sim$ $10.5 \mathrm{~W} \mathrm{~m}^{-2}$, weakened the partitioning into $\mathrm{SH}$ by $-13.3 \sim$ $9.4 \mathrm{~W} \mathrm{~m}^{-2}$, and increased $\alpha$ by $-0.01 \sim 0.05$.

The opposite conversions of land use type had inverse effects on the components of surface energy balance and $\alpha$ with little differences in variation amplitude. For example, the conversion from farm to grass mainly decreased $R_{\mathrm{n}}$ by $-3.2 \sim$ $1.1 \mathrm{~W} \mathrm{~m}^{-2}$, decreased LH by $-9.2 \sim 3.7 \mathrm{~W} \mathrm{~m}^{-2}$, decreased $\alpha$ by $-0.03 \sim 0.002$, and increased SH by $-7 \sim 12.3 \mathrm{~W} \mathrm{~m}^{-2}$. The key factors in controlling the variance were the difference of atmospheric data used in model. Puma et al. (2013) showed meteorological forcing had strong influence on transpiration and evapotranspiration. Our relative importance analysis indicated that radiation and precipitation had important relation with energy balance components; LAI variation in LUCC process regulated the surface energy partitioning. So the spatial variation of atmospheric data determined the asymmetrical pattern of the opposite conversions of land use type, and LAI constrained the change direction of the surface energy balance.

\subsubsection{The effects of LUCC on the variations of canopy temperature}

The LUCC types also changed the average of canopy temperature (Fig. 4a) and diurnal temperature range (Fig. 4b). The conversion from forest to grass increased $T_{\mathrm{c}}$ by up to $0.56{ }^{\circ} \mathrm{C}$ and decreased DTR by $-1.9 \sim 0.7^{\circ} \mathrm{C}$. The conversion from forest to farm caused the variation ranges of $T_{\mathrm{c}}$ and DTR between $-0.48 \sim 0.21$ and $-1.3 \sim 0.4{ }^{\circ} \mathrm{C}$, respectively. The variation amplitude of $T_{\mathrm{c}}$ and DTR would reach -1.24 and $2.2{ }^{\circ} \mathrm{C}$ for the conversion from grass to farm. The opposite conversion directions of land use change also resulted in reversed effects on $T_{\mathrm{c}}$ and DTR.
The spatial pattern of the influence of LUCC on the components of surface energy balance (Fig. 3) and climate (Fig. 4) demonstrated that LUCC exerted significant but not steady effects on $R_{\mathrm{n}}, \mathrm{LH}, \mathrm{SH}, \alpha, T_{\mathrm{c}}$, and DTR. For example, the conversion from farm to forest not only raised the $T_{\mathrm{c}}$ by $0.47{ }^{\circ} \mathrm{C}$ in some area but also lead to the reduction of $-0.26{ }^{\circ} \mathrm{C}$ in other area. The reasons could be ascribed to the influence of atmospheric forcing and the differences of land use types on vegetation characteristics. We chose LAI in morphological structure and $g_{\mathrm{c}}$ in physiological feature to analyze the influence of vegetation on surface energy balance and climate. The contributions of the components of surface energy balance were also displayed.

3.2 The influence of LAI and $g_{\mathrm{c}}$ on energy partitioning and canopy temperature

\subsubsection{The effects of LUCC on the variations of LAI and $g_{c}$}

The influences of LUCC on LAI and $g_{\mathrm{c}}$ were shown in Fig. 5. Forest had the highest LAI, the conversion from which to grass could decrease LAI by $-5.9 \sim-1.4 \mathrm{~m}^{2} \mathrm{~m}^{-2}$, and to farm by $-5.3 \sim-0.4 \mathrm{~m}^{2} \mathrm{~m}^{-2}$. The relative sizes of LAI at farm and grass were fluctuated in space. LAI at farm was usually higher than at grass. The transformation between grass and farm would cause a variation of $-0.4 \sim 2.3 \mathrm{~m}^{2} \mathrm{~m}^{-2}$ of LAI depending on the conversion direction. So, LAI at farm may be less than that at grass.

The variation of $g_{\mathrm{c}}$ was larger with the conversions of land use types. The conversions from forest to grass, from forest to farm, and from grass to farm changed $g_{\mathrm{c}}$ by $-0.05 \sim 0.03$, $-0.03 \sim 0.07$, and $-0.03 \sim 0.06 \mathrm{~mol} \mathrm{~m}^{-2} \mathrm{~s}^{-1}$, respectively. These, to some extent, were consistent with the changes of LH and $T_{\mathrm{c}}$.

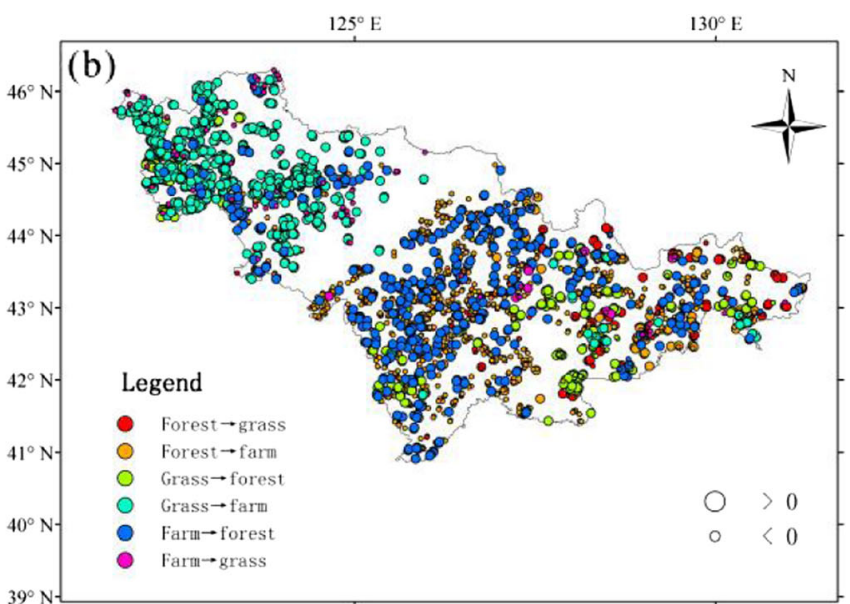

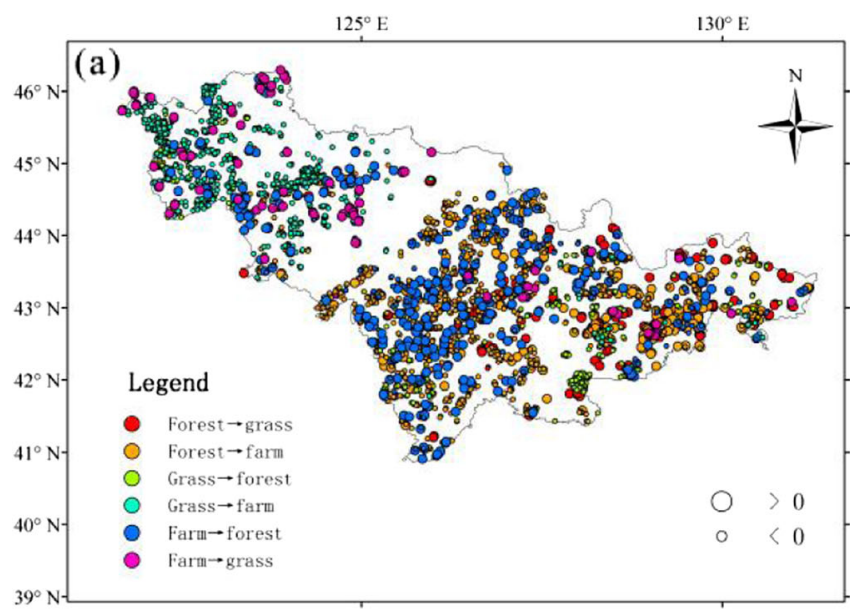

Fig. 4 The spatial pattern of LUCC-induced impacts on canopy temperature $\left(\mathbf{a},{ }^{\circ} \mathrm{C}\right)$ and diurnal temperature range $\left(\mathbf{b},{ }^{\circ} \mathrm{C}\right)$. Large $($ small $)$ circle represents a positive (negative) impact 

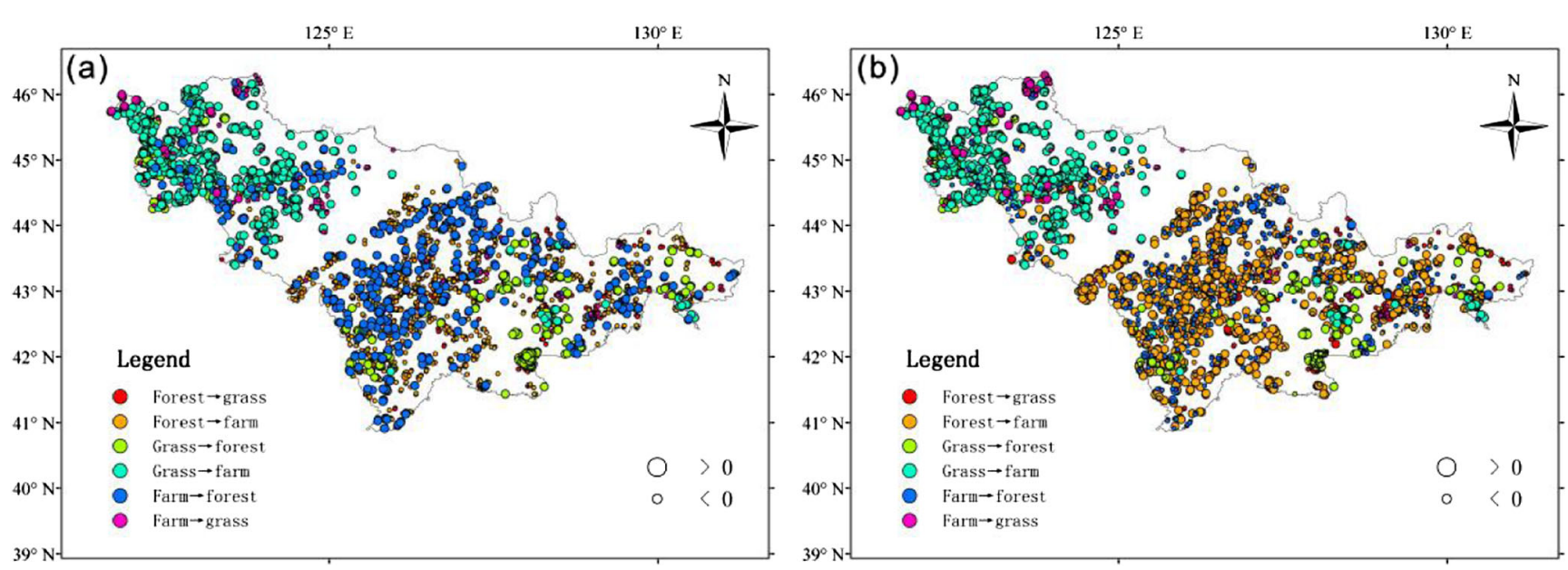

Fig. 5 The spatial pattern of LUCC-induced impacts on leaf area index $\left(\mathbf{a}, \mathrm{m}^{2} \mathrm{~m}^{-2}\right)$ and canopy conductance $\left(\mathbf{b}\right.$, mol $\left.\mathrm{m}^{-2} \mathrm{~s}^{-1}\right)$. Large (small) circle represents a positive (negative) impact

\subsubsection{The contribution of vegetation to surface energy balance and climate}

The linear correlations between the components of surface energy balance, $T_{\mathrm{c}}$, DTR and LAI, $g_{\mathrm{c}}$ were analyzed to show the role of vegetation in regulating surface energy balance and climate. It was shown that $\mathrm{LH}, \alpha$, and $T_{c}$ were especially highly correlated with LAI and $g_{\mathrm{c}}\left(R^{2}\right.$ usually greater than $0.5, p<0.001)$ of all land use types at seasonal scale. LAI and $g_{\mathrm{c}}$ also modified the seasonal change patterns of $R_{\mathrm{n}}, \mathrm{SH}$, and DTR (data not shown).

The change of LAI and $g_{\mathrm{c}}$ explained much of the variations of surface energy balance, but less of $T_{\mathrm{c}}$, and DTR (Table 2). Under all LUCC scenarios, $\triangle \mathrm{LH}$ and $\triangle \mathrm{SH}$ were highly correlated with $\Delta \mathrm{LAI}$ and $\Delta g_{\mathrm{c}}$. The results suggested the linear relationship between LAI and LH of all land use types. And LH (SH) was raised (reduced) with the increase of LAI and $g_{\mathrm{c}}$, which means LAI and $g_{\mathrm{c}}$ would enhance the partitioning of $R_{\mathrm{n}}$ into LH. $R_{\mathrm{n}}$ and $\alpha$ had certain relevance with LAI under particular LUCC scenario.

The intercept of fitting equation had special meaning. For instant, $\Delta \mathrm{LAI}=0$, the equation of $\mathrm{y}=1.52 \mathrm{x}-9.69$ between $\Delta$ LAI and $\Delta R_{\mathrm{n}}$ indicated that other factors except LAI resulted in reduction of $R_{\mathrm{n}}$ about $9.69 \mathrm{~W} \mathrm{~m}^{-2}$ under the conversion between forest to grass. But special attention should be paid to the scope of $x$ axis, which controls the variation ranges of variable $y$. For example, since $\Delta$ LAI ranged between -5.9 and $-1.4 \mathrm{~m}^{2} \mathrm{~m}^{-2}$, the variation amplitude of $\Delta R_{\mathrm{n}}$ should be limited between -18.66 and $-11.82 \mathrm{~W} \mathrm{~m}^{-2}$. The scope of $x$ was shown in Fig. 5,

Table 2 The linear correlations between the gaps of LAI, $g_{\mathrm{c}}$, and the gaps of the components of surface energy balance, $T_{\mathrm{c}}$, and DTR induced by different LUCC scenarios

\begin{tabular}{|c|c|c|c|c|c|c|c|}
\hline LUCC & Item & $\Delta R_{\mathrm{n}}$ & $\Delta \mathrm{LH}$ & $\Delta \mathrm{SH}$ & $\Delta \alpha$ & $\Delta T_{\mathrm{c}}$ & $\Delta \mathrm{DTR}$ \\
\hline \multirow[t]{2}{*}{ LUCC1 } & $\Delta \mathrm{LAI}$ & $\begin{array}{l}y=1.52 \mathrm{x}-9.69 \\
R^{2}=0.79\end{array}$ & $\begin{array}{l}y=3.18 \mathrm{x}+12.70 \\
R^{2}=0.92\end{array}$ & $\begin{array}{l}y=-1.79 \mathrm{x}-22.84 \\
R^{2}=0.63\end{array}$ & $\begin{array}{l}y=-0.011 \mathrm{x}+0.033 \\
R^{2}=0.74\end{array}$ & $\begin{array}{l}y=0.017 \mathrm{x}+0.3 \\
R^{2}=0.029\end{array}$ & $\begin{array}{l}y=-0.27 \mathrm{x}-1.45 \\
R^{2}=0.7\end{array}$ \\
\hline & $\Delta \mathrm{g}_{\mathrm{c}}$ & $\begin{array}{l}y=97.61 \mathrm{x}-14.53 \\
R^{2}=0.26\end{array}$ & $\begin{array}{l}y=308.74 \mathrm{x}+3.13 \\
R^{2}=0.71\end{array}$ & $\begin{array}{l}y=-223.61 \mathrm{x}-17.7 \\
R^{2}=0.8\end{array}$ & $\begin{array}{l}y=-0.6059 \mathrm{x}+0.067 \\
R^{2}=0.19\end{array}$ & $\begin{array}{l}y=-2.79 \mathrm{x}+0.22 \\
R^{2}=0.067\end{array}$ & $\begin{array}{l}y=-18.54 \mathrm{x}-0.59 \\
R^{2}=0.27\end{array}$ \\
\hline \multirow[t]{2}{*}{ LUCC2 } & $\Delta \mathrm{LAI}$ & $\begin{array}{l}y=1.37 \mathrm{x}-11.29 \\
R^{2}=0.47\end{array}$ & $\begin{array}{l}y=3.49 \mathrm{x}+14.04 \\
R^{2}=0.86\end{array}$ & $\begin{array}{l}y=-2.3 \mathrm{x}-25.77 \\
R^{2}=0.56\end{array}$ & $\begin{array}{l}y=-0.0072 \mathrm{x}+0.065 \\
R^{2}=0.36\end{array}$ & $\begin{array}{l}y=-0.061 \mathrm{x}-0.21 \\
R^{2}=0.32\end{array}$ & $\begin{array}{l}y=-0.121 \mathrm{x}-0.68 \\
R^{2}=0.32\end{array}$ \\
\hline & $\Delta \mathrm{g}_{\mathrm{c}}$ & $\begin{array}{l}y=45.12 \mathrm{x}-15.19 \\
R^{2}=0.083\end{array}$ & $\begin{array}{l}y=248.52 x+1.29 \\
R^{2}=0.7\end{array}$ & $\begin{array}{l}y=-214.02 \mathrm{x}-16.34 \\
R^{2}=0.79\end{array}$ & $\begin{array}{l}y=-0.14 \mathrm{x}+0.084 \\
R^{2}=0.021\end{array}$ & $\begin{array}{l}y=-5.12 \mathrm{x}+0.031 \\
R^{2}=0.37\end{array}$ & $\begin{array}{l}y=-7.11 \mathrm{x}-0.26 \\
R^{2}=0.18\end{array}$ \\
\hline \multirow[t]{2}{*}{ LUCC3 } & $\Delta \mathrm{LAI}$ & $\begin{array}{l}y=-0.97 \mathrm{x}+1.98 \\
R^{2}=0.098\end{array}$ & $\begin{array}{l}y=3.52 \mathrm{x}-0.26 \\
R^{2}=0.58\end{array}$ & $\begin{array}{l}y=-4.7 x+2.25 \\
R^{2}=0.45\end{array}$ & $\begin{array}{l}y=0.0091 \mathrm{x}+0.0093 \\
R^{2}=0.29\end{array}$ & $\begin{array}{l}y=-0.073 x-0.63 \\
R^{2}=0.0069\end{array}$ & $\begin{array}{l}y=-0.13 \mathrm{x}+0.66 \\
R^{2}=0.027\end{array}$ \\
\hline & $\Delta \mathrm{g}_{\mathrm{c}}$ & $\begin{array}{l}y=-14.15 x+1.64 \\
R^{2}=0.021\end{array}$ & $\begin{array}{l}y=122.78 \mathrm{x}-0.25 \\
R^{2}=0.73\end{array}$ & $\begin{array}{l}y=-146.8 x+1.94 \\
R^{2}=0.45\end{array}$ & $\begin{array}{l}y=0.42 \mathrm{x}+0.0076 \\
R^{2}=0.62\end{array}$ & $\begin{array}{l}y=-9.68 x-0.51 \\
R^{2}=0.12\end{array}$ & $\begin{array}{l}y=2.82 x+0.53 \\
R^{2}=0.013\end{array}$ \\
\hline
\end{tabular}

LUCC1 represents the conversion from forest to grass, LUCC2 represents the conversion from forest to farm, and LUCC 3 represents the conversion from grass to farm. Fitted equations contained the reverse direction of LUCC1, LUCC2, and LUCC3. The same below 
and the calculated outcomes coincide with the results in Fig. 3.

The determination coefficients of $\Delta T_{\mathrm{c}}$ and $\Delta \mathrm{DTR}$ were usually low (Table 2). So the differences of $T_{\mathrm{c}}$ and DTR cannot be linearly explained by the variation of LAI. The surface energy balance had more explanatory power for $\triangle \mathrm{DTR}$ as shown in Table 3. And $R_{\mathrm{n}}$ was the better factor than $\mathrm{LH}$ and SH in explaining the variation of $\Delta \mathrm{DTR}$. But $\Delta T_{\mathrm{c}}$ still was not well-explained. The reason is that $T_{\mathrm{c}}$ is influenced by both radiative and non-radiative processes. These two processes are really important and have opposite effects on $T_{\mathrm{c}}$ regulation. So single-reason method cannot well fit the change of $T_{\mathrm{c}}$. We further calculated the contributions of $\alpha$ to $T_{\mathrm{c}}$ to illustrate the influence of energy partitioning on climate, using Eqs. (1 and 3).

\subsection{The contribution of energy partitioning to canopy temperature}

LUCC influenced the surface energy balance. Overall, $R_{\mathrm{n}}$ and $\mathrm{LH} / R_{\mathrm{n}}$ were reduced and $\alpha$ were increased at farm or grass converted from forest (Table 4). The conversion from grass to farm could increase $R_{\mathrm{n}}, \mathrm{LH} / R_{\mathrm{n}}$, and $\alpha$. Albedo determined the short-wave radiation absorption of ecosystem. The change of $R_{\mathrm{n}}$ was in correspondence with the variation of $\alpha$ in most case. But energy partitioning of $R_{\mathrm{n}}$ into $\mathrm{SH}$ imposed significant impact on emitted long-wave radiation, which can retard or

Table 3 The linear correlations between the gaps of the components of surface energy balance and the gaps of $T_{\mathrm{c}}$ and DTR induced by different LUCC scenarios

\begin{tabular}{|c|c|c|c|}
\hline LUCC & Item & $\Delta T_{\mathrm{c}}$ & $\Delta \mathrm{DTR}$ \\
\hline \multirow[t]{3}{*}{ LUCC1 } & $\Delta \mathrm{R}_{\mathrm{n}}$ & $\begin{array}{l}y=0.022 \mathrm{x}+0.56 \\
R^{2}=0.15\end{array}$ & $\begin{array}{l}y=-0.17 x-3.07 \\
R^{2}=0.82\end{array}$ \\
\hline & $\Delta \mathrm{LH}$ & $\begin{array}{l}y=0.0042 \mathrm{x}+0.23 \\
R^{2}=0.021\end{array}$ & $\begin{array}{l}y=-0.081 \mathrm{x}-0.37 \\
R^{2}=0.68\end{array}$ \\
\hline & $\Delta \mathrm{SH}$ & $\begin{array}{l}y=0.003 \mathrm{x}+0.29 \\
R^{2}=0.005\end{array}$ & $\begin{array}{l}y=0.082 \mathrm{x}+0.86 \\
R^{2}=0.32\end{array}$ \\
\hline \multirow[t]{3}{*}{ LUCC2 } & $\Delta \mathrm{R}_{\mathrm{n}}$ & $\begin{array}{l}y=-0.03 x-0.5 \\
R^{2}=0.31\end{array}$ & $\begin{array}{l}y=-0.073 x-1.45 \\
R^{2}=0.46\end{array}$ \\
\hline & $\Delta \mathrm{LH}$ & $\begin{array}{l}y=-0.016 \mathrm{x}+0.029 \\
R^{2}=0.32\end{array}$ & $\begin{array}{l}y=-0.038 x-0.17 \\
R^{2}=0.45\end{array}$ \\
\hline & $\Delta \mathrm{SH}$ & $\begin{array}{l}y=0.013 \mathrm{x}+0.2 \\
R^{2}=0.14\end{array}$ & $\begin{array}{l}y=0.03 x+0.2 \\
R^{2}=0.18\end{array}$ \\
\hline \multirow[t]{3}{*}{ LUCC3 } & $\Delta \mathrm{R}_{\mathrm{n}}$ & $\begin{array}{l}y=-0.21 \mathrm{x}-0.39 \\
R^{2}=0.57\end{array}$ & $\begin{array}{l}y=0.098 \mathrm{x}+0.44 \\
R^{2}=0.15\end{array}$ \\
\hline & $\Delta \mathrm{LH}$ & $\begin{array}{l}y=0.012 \mathrm{x}-0.7 \\
R^{2}=0.0041\end{array}$ & $\begin{array}{l}y=-0.01 \mathrm{x}+0.6 \\
R^{2}=0.0036\end{array}$ \\
\hline & $\Delta \mathrm{SH}$ & $\begin{array}{l}y=-0.044 x-0.71 \\
R^{2}=0.12\end{array}$ & $\begin{array}{l}y=0.022 \mathrm{x}+0.59 \\
R^{2}=0.039\end{array}$ \\
\hline
\end{tabular}

Table 4 The influences of LUCC on surface energy balance and its contributions to climate

\begin{tabular}{lrlllll}
\hline & \multicolumn{1}{c}{$\Delta R_{\mathrm{n}}$} & $\Delta \mathrm{LH} / R_{\mathrm{n}}$ & $\Delta \alpha$ & $\Delta T_{\mathrm{c}}$ & $\Delta T_{\alpha}$ & $\Delta \mathrm{DTR}$ \\
\hline LUCC1 & -15.15 & -0.33 & 0.072 & -0.08 & -2.59 & -0.44 \\
LUCC2 & -14.06 & -0.21 & 0.08 & -0.35 & -2.82 & -0.43 \\
LUCC3 & 1.26 & 0.011 & 0.013 & -0.59 & -0.43 & 0.52 \\
\hline
\end{tabular}

LH $/ R_{\mathrm{n}}$ means the partitioning of $R_{\mathrm{n}}$ into LH. $T_{\alpha}$ means the canopy temperature variation caused by $\alpha$

reverse the relationship between $\Delta R_{\mathrm{n}}$ and $\Delta \alpha$. It was clear for the conversion from grass to farm that $R_{\mathrm{n}}$ was increased but $\alpha$ also increased. Less $R_{\mathrm{n}}$ was partitioned into $\mathrm{SH}$ at farm, which means the emitted long-wave radiation was decreased. So the loss of net long-wave radiation was decreased, then $R_{\mathrm{n}}$ increased. Energy partitioning made some contribution to $R_{\mathrm{n}}$.

Energy partitioning also had important influences on canopy temperature (Table 4). The simulated results of $\Delta T_{\mathrm{c}}$ were $-0.08,-0.35$, and $-0.59^{\circ} \mathrm{C}$ for the conversion from forest to grass, from forest to farm, and from grass to farm, respectively. But the gaps should be $-2.59,-2.82$, and -0.43 , respectively, sole considering the differences of $\alpha$. The energy partitioning greatly modified the interrelations of $T_{\mathrm{c}}$ for different LUCC. The difference between $\Delta T_{\alpha}$ and $\Delta T_{\mathrm{c}}$ could be the role of non-radiative process. The non-radiative process partially dampened or strengthened the temperature difference between vegetation types. The decrease of $\Delta \mathrm{LH} / R_{\mathrm{n}}$ in LUCC1 and LUCC2 suggests that forest had larger ability in allocating net radiation into latent heat than grass and farm. Although grass and farm captured less net radiation, most of energy was used to warm air, which raised the canopy temperature. LUCC also impacted the DTR, which with the change of $R_{\mathrm{n}}$.

\section{Discussion and conclusions}

In this study, we investigated the different responses to LUCC (between forest, grass, and farm) of canopy temperature and surface energy balance in northeast China's Jilin Province, using a coordinated set of experiments carried out by SiB2. We focused on the spatial patterns of the components of surface energy balance and canopy temperature, and the contributions of land cover type in variations of energy balance and temperature in the LUCC process.

Land cover controls many feedbacks of vegetation to surface energy balance by influencing leaf area index, albedo, surface roughness length, and canopy conductance. Falge et al. (2002) found that the major factors affecting the seasonal course of LH are seasonal changes in LAI and physiological capacity of the plants in terms of stomatal control, and 
replacing forest with other land cover may change the proportions of energy going into latent and sensible flux because of differences in LAI, aerodynamic roughness, root depth, and stomatal behavior. The observational data had been used to present the importance of LAI, stomatal behavior, and soil moisture in energy partitioning at temperate grassland (Baldocchi et al. 2004; Hammerle et al. 2008; Li et al. 2006), at deciduous or needle-leaf forest (Barr et al. 2009; $\mathrm{Gu}$ et al. 2006), and at cropland (Iritz and Lindroth 1996; Li et al. 2009). Our simulation results showed that LAI and $g_{c}$ had great corresponding relationships with net radiation, latent heat, sensible heat, and albedo in spatial pattern, and these relationships must be linearly as proved by the well explanations of $\Delta \mathrm{LAI}$ and $\Delta g_{\mathrm{c}}$ on $\Delta R_{\mathrm{n}}, \Delta \mathrm{LH}, \Delta \mathrm{SH}$, and $\Delta \alpha$ (Table 2).

The key parameters determining the influences of LUCC on climate are LAI, albedo, and root depth (Pielke et al. 2007; Mahmood et al. 2013). In one GCM simulation using MODIS data, it showed that the surface albedo value for cropland is of major importance in climate simulations of land cover change, and surface albedo effect is the main driving mechanism when the change in surface albedo between agricultural and natural vegetation is substantial (Bonan 2013). Root depth determines the amount of available water especially in dry season, which controls the transpiration of plant (Bonan 2002). The impacts of LAI on canopy temperature and diurnal temperature range were clear in our analyses (Figs. 5). But these affects were not linear relationship (Table 2). So the linear relationships between $\Delta T_{\mathrm{c}}, \Delta \mathrm{DTR}$, and the components of surface energy balance were further checked to reveal the most relevant factors. The results showed that $R_{\mathrm{n}}$ was the better factor than LH and SH in explaining the variations of DTR (Table 3). When the albedo gap was small, surface energy partitioning even changed the relative size of albedo-based $R_{\mathrm{n}}$ between land cover, which is a new discovery.

The deforestation activity resulted in cooling consequence due to albedo effect in our study area (Lawrence and Chase 2010; Wang et al. 2013). But the albedo-cooling effect could be dampened by 30 to $50 \%$ by non-radiative process (Boisier et al. 2012). The calculation results based on Eq. (1 and 2) confirmed this modifying effects (Table 4). The obvious transformation was forest reclamation into farmland and grassland into farmland (Fig. 2). So, the effect of LUCC on temperature was cooling, which coincides with other researcher (Lawrence and Chase 2010; Wang et al. 2013). Dong et al. (2013) also found that the temperature reduction mainly happened in summer in the central northeastern area.

The observational data showed that DTR ranged between 12.3 and $17.4{ }^{\circ} \mathrm{C}$ at forest, and $12.8-17.8^{\circ} \mathrm{C}$ at farm or at grass, respectively (Dai et al. 1999). Bounoua et al. (2006) found the DTR varies from 13 to $15{ }^{\circ} \mathrm{C}$ depending on the dominant type. DTR is severely affected by clouds, soil water content, precipitation, and atmospheric water vapor (Dai et al.
1999). And significant impact of LAI on it was found in SiB2 simulation by Bounoua et al. (2006). The DTR variation amplitude could be determined by the daily maximum temperature. On global scale, land use changes have induced a significant cooling in warm extremes of daily temperature (Christidis et al. 2013). The conversion from Canadian prairies into farmland greatly decreased the maximum temperature and DTR in summer but increased the maximum temperature and DTR in other time (Betts et al. 2013).

Acknowledgments This study was supported by the National Key Program for Developing Basic Science (Project Number 2010CB950902), China. We thank the anonymous reviewer for the constructive comments and suggestions on our manuscript.

\section{References}

Avila F, Pitman A, Donat M, Alexander L, Abramowitz G (2012) Climate model simulated changes in temperature extremes due to land cover change. J Geophys Res 117:D04108. doi:10.1029/2011jd016382

Baldocchi DD, Vogel CA, Hall B (1997) Seasonal variation of energy and water vapor exchange rates above and below a boreal jack pine forest canopy. J Geophys Res 102:28939-28951

Baldocchi DD, Xu L, Kiang N (2004) How plant functional-type, weather, seasonal drought, and soil physical properties alter water and energy fluxes of an oak-grass savanna and an annual grassland. Agr Forest Meteorol 123:13-39

Barr A, Black TA, McCaughey H (2009) Climatic and phenological controls of the carbon and energy balances of three contrasting boreal forest ecosystems in western Canada. Pages. In Phenology of Ecosystem Precesses (pp. 3-34). Springer New York

Betts RA (2001) Biogeophysical impacts of land use on present-day climate: near-surface temperature change and radiative forcing. Atmos Sci Lett 2:39-51

Betts RA, Falloon PD, Goldewijk KK, Ramankutty N (2007) Biogeophysical effects of land use on climate: model simulations of radiative forcing and large-scale temperature change. Agric For Meteorol 142:216-233

Betts AK, Desjardins R, Worth D, Cerkowniak D (2013) Impact of land use change on the diurnal cycle climate of the Canadian Prairies. J Geophys Res 118(21):11,996-12,011

Boisier JP, de Noblet-Ducoudré N, Pitman AJ, Cruz FT, Delire C, van den Hurk BJJM, van der Molen MK, Müller C, Voldoire A (2012) Attributing the impacts of land-cover changes in temperate regions on surface temperature and heat fluxes to specific causes: results from the first LUCID set of simulations. J Geophys Res 117: D12116. doi:10.1029/2011JD017106

Bonan GB (2002) Ecological climatology: concepts and applications: Cambridge University Press

Bonan GB (2008) Forests and climate change: forcings, feedbacks, and the climate benefits of forests. Science 320:1444-1449

Bonan GB (2013) Biogeophysical feedbacks between land cover and climate. In: Defries RS, Asner GP, Houghton RA (eds) Ecosystems and land use change. American Geophysical Union, Washington, DC, pp 61-72. doi:10.1029/153GM06

Bounoua L, Masek J, Tourre YM (2006) Sensitivity of surface climate to land surface parameters: a case study using the simple biosphere model SiB2. J Geophys Res 111(D22S09):1984-2012. doi:10.1029/ 2011JD016382 
Cesaraccio C, Spano D, Duce P, Snyder RL (2001) An improved model for determining degree-day values from daily temperature data. Int J Biometeorol 45:161-169

Christidis N, Stott PA, Hegerl GC, Betts RA (2013) The role of land use change in the recent warming of daily extreme temperatures. Geophys Res Lett 40(3):589-594

Collatz GJ, Ball JT, Grivet C, Berry JA (1991) Physiological and environmental regulation of stomatal conductance, photosynthesis and transpiration: a model that includes a laminar boundary layer. Agric For Meteorol 54(2-4):107-136

Collatz GJ, Ribas-Carbo M, Berry JA (1992) Coupled photosynthesisstomatal conductance model for leaves of C4 plants. Aust J Plant Physiol 19:519-538

Dai A, Trenberth KE, Karl TR (1999) Effects of clouds, soil moisture, precipitation, and water vapor on diurnal temperature range. J Clim 12:2451-2473

Dong SY, Yan XD, Xiong Z (2013) Varying responses in mean surface air temperature from land use/cover change in different seasons over Northern China. Acta Ecol Sin 33(3):167-171

Falge E, Tenhunen J, Baldocchi D, Aubinet M, Bakwin P (2002) Phase and amplitude of ecosystem carbon release and uptake potentials as derived from FLUXNET measurements. Agric For Meteorol 113(1):75-95

Feddema J, Oleson K, Bonan G, Mearns L, Washington W, Meehl G, Nychka D (2005) A comparison of a GCM response to historical anthropogenic land cover change and model sensitivity to uncertainty in present-day land cover representations. Clim Dyn 25:581609

Gao X, Luo Y, Lin W, Zhao Z, Filippo G (2003) Simulation of effects of land use change on climate in China by a regional climate model. Adv Atmos Sci 20:583-592

Gu L, Meyers T, Pallardy SG, Hanson PJ, Yang B, Heuer M, Hosman KP, Riggs JS, Sluss D, Wullschleger SD (2006) Direct and indirect effects of atmospheric conditions and soil moisture on surface energy partitioning revealed by a prolonged drought at a temperate forest site. J Geophys Res 111:D16102. doi:10.1029/2006JD007161

Hammerle A, Haslwanter A, Tappeiner U, Cernusca A, Wohlfahrt G (2008) Leaf area controls on energy partitioning of a temperate mountain grassland. Biogeosciences 5:421-431

Hanan NP, Berry JA, Verma SB, Walter-Shea EA, Suyker AE, Burba GG, Denning AS (2005) Testing a model of $\mathrm{CO}_{2}$, water and energy exchange in great plains tallgrass prairie and wheat ecosystems. Agric For Meteorol 131:162-179

IPCC (2007) Climate change 2007. In: Solomon S, Qin D, Manning M, Chen Z, Marquis M, Averyt KB, Tignor M, Miller HL (eds) The physical science basis. Contribution of working group I to the fourth assessment report of the intergovernmental panel on climate change. Cambridge University Press, Cambridge

Iritz Z, Lindroth A (1996) Energy partitioning in relation to leaf area development of short-rotation willow coppice. Agric For Meteorol $81: 119-130$

Kimball JS, Running SW, Nemani R (1997) An improved method for estimating surface humidity from daily minimum temperature. Agric For Meteorol 85:87-98

Lawrence PJ, Chase TN (2010) Investigating the climate impacts of global land cover change in the community climate system model. Int J Climatol 30:2066-2087

Li SG, Eugster W, Asanuma J, Kotani A, Davaa G, Oyunbaatar D, Sugita M (2006) Energy partitioning and its biophysical controls above a grazing steppe in central Mongolia. Agric For Meteorol 137:89-106

Li Y, Zhou L, Xu Z, Zhou G (2009) Comparison of water vapour, heat and energy exchanges over agricultural and wetland ecosystems. Hydrol Process 23:2069-2080

Liang SL, Xiao ZQ (2012) Global land surface products: leaf area index product data collection(1985-2010). Beijing, China: Beijing Normal University, http://www.bnu-datacenter.com/
Liu JY, Liu ML, Deng XZ, Zhuang DF, Zhang ZX, Luo D (2002) The land use and land cover change database and its relative studies in China. J Geogr Sci 12:275-282

Liu JY, Zhang ZX, Xu XL, Kuang WH, Zhou WC, Zhang SW, Li RD, Yan CZ, Yu DS, Wu SX, Jiang N (2009) Spatial patterns and driving forces of land use change in China in the early 21 st century. Acta Geograph Sin 64:1411-1420 (in Chinese with English abstract)

Liu FS, Tao FL, Xiao DP, Zhang S, Wang M, Zhang H (2014) The influence of land use change on surface energy balance and climate: results from SiB2 model simulation. Prog Geogr 33:815-824

Mahmood R, Pielke RA, Hubbard KG, Niyogi D, Dirmeyer PA, McAlpine C, Carleton AM, Hale R, Gameda S, Beltrán-Przekurat A (2013) Land cover changes and their biogeophysical effects on climate. Int J Climatol 34:929-953. doi:10.1002/joc.3736

Pielke R, Adegoke J, Beltran-Przekurat A, Hiemstra C, Lin J, Nair U, Niyogi D, Nobis T (2007) An overview of regional land-use and land-cover impacts on rainfall. Tellus B 59:587-601

Pongratz J, Bounoua L, DeFries RS, Morton DC, Anderson LO, Mauser W, Klink CA (2006) The impact of land cover change on surface energy and water balance in Mato Grosso, Brazil. Earth Interact 10: $1-17$

Potter CS, Randerson JT, Field CB, Matson PA, Vitousek PM, Mooney HA, Klooster SA (1993) Terrestrial ecosystem production: a process model based on global satellite and surface data. Global Biogeochem Cycles 7:811-841

Puma MJ, Koster RD, Cook BI (2013) Phenological versus meteorological controls on land-atmosphere water and carbon fluxes. J Geophys Res Biogeosci 118:14-29

Revfeim KJA (1997) On the relationship between radiation and mean daily sunshine. Agric For Meteorol 86:183-191

Sellers PJ (1985) Canopy reflectance, photosynthesis and transpiration. Int J Remote Sens 6:1335-1372

Sellers PJ, Randall D, Collatz G, Berry J, Field C, Dazlich D, Zhang C, Collelo G, Bounoua L (1996a) A revised land surface parameterization (SiB2) for atmospheric GCMs. Part I: model formulation. J Clim 9:676-705

Sellers PJ, Tucker CJ, Collatz GJ, Los SO, Justice CO, Dazlich DA, Randall DA (1996b) A revised land surface parameterization (SiB2) for atmospheric GCMs. Part II: the generation of global fields of terrestrial biophysical parameters from satellite data. J Clim 9:706-737

Tang Q, Oki T, Kanae S (2006) A distributed biosphere hydrological model (DBHM) for large river basin. P Hydraul Eng 50:37-42

Teuling AJ, Seneviratne SI, Stockli R, Reichstein M, Moors E, Ciais P, Luyssaert S, van den Hurk B, Ammann C, Bernhofer C, Dellwik E, Gianelle D, Gielen B, Grunwald T, Klumpp K, Montagnani L, Moureaux C, Sottocornola M, Wang L, Koike T, Yang D, Yang K (2009) Improving the hydrology of the simple biosphere model 2 and its evaluation within the framework of a distributed hydrological model. Hydrol Sci J 54:989-1006

Wang Q, Niu D, Yu G, Ren Z, Wen X, Chen J, Ju W (2004) Simulating the exchange of carbon dioxide, water vapor and heat over Changbai mountains temperate broad-leaved Korean pine mixed forest ecosystem. Sci China Ser D 34:131-140 (in Chinese with English abstract)

Wang YL, Feng JM, Gao H (2013) Numerical simulation of the impact of land cover change on regional climate in China. Theor Appl Climatol 115(1-12):141-152

Yan XD, Li HY, Liu F, Gao ZQ, Liu HZ (2010) Modeling of surface flux in Tongyu using the simple biosphere model 2 (SiB2). J For Res 21(2):183-188

Yang K, Huang GW, Tamai N (2001) A hybrid model for estimating global solar radiation. Sol Energy 70(1):13-22

Zhao S, Fang J, Zong Z, Zhu B, Shen H (2004) Composition, structure and species diversity of plant communities along an altitudinal gradient on the northern slope of Mt. Changbai, Northeast China. Biodivers Sci 12(1):164-173 (in Chinese with English abstract) 